\title{
Properties Of Fine Dust Adsorption Matrix According To The Powdered Activated Carbon Mixing Method Based On Blast Furnace Slag
}

\author{
YeonHo Kim, EunSeok Jo and SangSoo Lee * \\ ${ }^{1}$ Master's Course, Department of Architectural Engineering, Hanbat National Univ, Daejeon, 34158, Korea. \\ ${ }^{2}$ Doctor's Course, Department of Architectural Engineering, Hanbat National Univ, Daejeon, 34158, Korea. \\ ${ }^{3}$ Proofessor, Department of Architectural Engineering, Hanbat National Univ, Daejeon, 34158, Korea. \\ *Corresponding author. Tel.: +82-010-3324-3992; Email address: sslee111@ hanbat.ac.kr
}

Article History:Received:11 november 2020; Accepted: 27 December 2020; Published online: 05 April 2021

\begin{abstract}
Due to the increase in fine dust caused by deepening air pollution, interest in the adverse effects of fine dust has increased. In this study, an experiment was conducted by applying a physical adsorption mechanism to the matrix to evaluate the properties of the microdust adsorption matrix. Density, absorption rate, fluidity, thermal conductivity, strength, and fine dust adsorption tests were conducted as test items for the evaluation of the physical properties of the matrix mixed with blast furnace slag-based powdered activated carbon. In this study, powdered activated carbon was used as a material for adsorbing fine dust. The results of the experiment for fabricating a fine dust adsorption matrix using powdered activated carbon are as follows. As the mixing ratio of powdered activated carbon increased, the density and absorption ratio tended to decrease and the absorption ratio increased. The flowability test showed a tendency to decrease as the mixing ratio of powdered activated carbon increased. As a result of the thermal conductivity test measurement, as the mixing ratio of powdered activated carbon increased, it decreased due to the increase of voids. As a result of the fine dust measurement, the higher the mixing ratio of powdered activated carbon was, the more the concentration tended to decrease due to the physical adsorption action. Compared to previous experiments using photocatalysts, it has been confirmed that overall performance such as strength has decreased, so a solution is needed.
\end{abstract}

Keywords: fine dust, indoor air quality, blast furnace slag, powdered activated carbon, adsorption.

\section{Introduction}

Recently, regardless of the season, the smog phenomenon and fine dust are threatening our health, especially in the metropolitan area. Fine dust is one of air pollutants, which is generated by industrial development, and is produced in various combustion, production, and manufacturing processes such as oil and cement manufacturing processes, waste incineration processes, and hazardous material processing processes. Fine dust from nature, yellow dust and pollen are relatively large. On the other hand, the fine dust from automobile exhaust and factory chimneys is very small. The smoke of thermal power plants also contains sulfur dioxide and nitrogen compounds[1].

Fine dust is a suspended solid in the air that refers to dust whose particles are so small that it is indistinguishable to the eye, and can be classified according to its diameter. Dust less than $10 \mu \mathrm{m}$ is defined as fine dust (PM10), dust less than $2.5 \mu \mathrm{m}$ is defined as ultrafine dust (PM2.5). It is divided into components (sulfate, nitrate, ammonium) and mineral components[2]. At present, there are domestic causes of environmental pollution caused by the use of fossil fuels and automobile emissions, and the inflow of fine dust from China due to the relocation of factories. In 2015, the HEI Institute for Health Impact reported that Korea's ultra-fine dust concentration was the second highest among OECD countries[3].

Due to these problems, social interest in indoor air pollution is increasing. Many studies have been conducted to purify the pollution level of indoor air quality, and research is needed for the development of construction materials with self-purification ability. In this study, the characteristics of adsorptive cured product substituted with photocatalyst carbon were evaluated[4,5,6]. [Figure 1, Figure 2] show pictures of fine dust and the causes of the occurrence of fine dust.

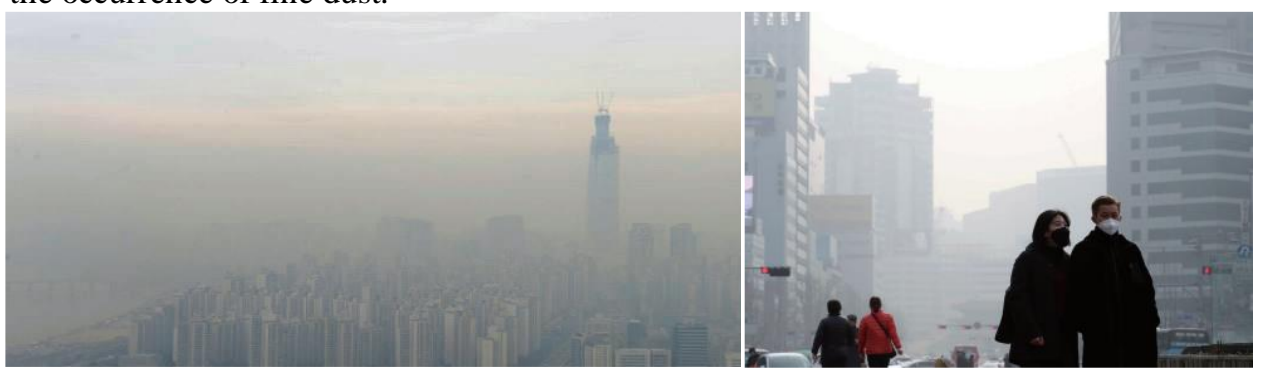

Figure 1 Korea's fine dust

*Corresponding author: SangSoo Lee

Proofessor, Department of Architectural Engineering, Hanbat National Univ, Daejeon, 34158, Korea.

Email address: sslee111@hanbat.ac.kr 


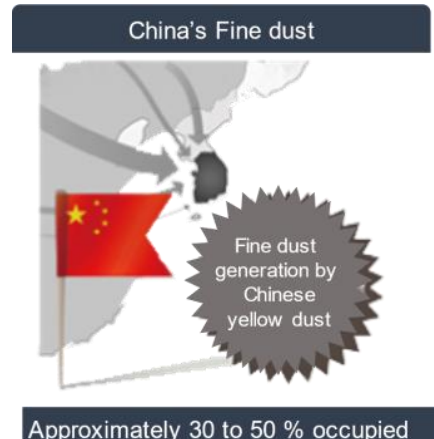

Approximately 30 to $50 \%$ occupied

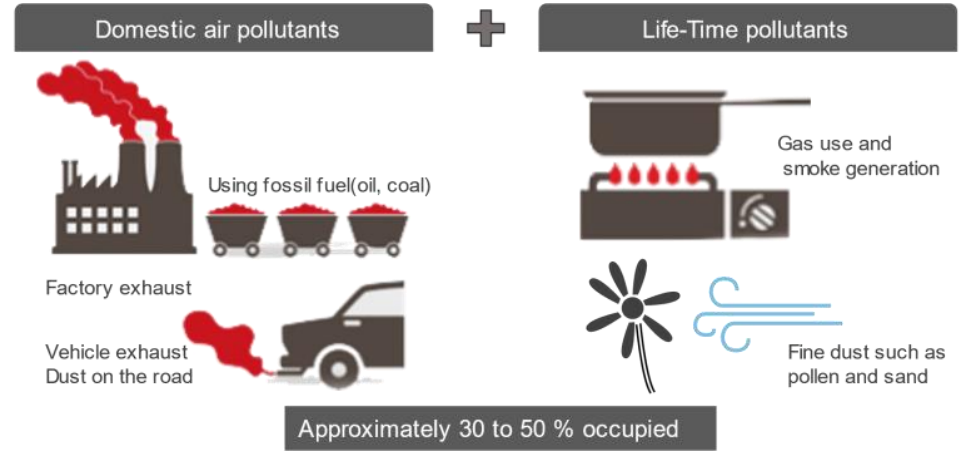

Figure 2 Fine dust generation factor

\section{Experimental plan and method}

Adsorption is a method of removing contaminated gas by using strong adsorption power to molecules and atoms of the gas due to chemical bonding or physical filling of the micropores on the surface of a solid micropores composed of a molecular layer. Physical adsorption, ionic bonds, and chemical adsorption occur through covalent bonding forces by van der Waals force. However, physical adsorption and chemical adsorption exist in the adsorption of activated carbon. Vapor adsorption has a lot of reversible physical adsorption, and liquid adsorption has a lot of irreversible chemical adsorption. The efficiency of the adsorption tower can be varied depending on design factors such as control of the contact time between the adsorbent and pollutant gas and the type of adsorbent selected.[7,8]

\subsection{Experimental plan}

In this study, the characteristics of the fine dust adsorption matrix were evaluated. The powdered activated carbon for adsorption of blast furnace slag and fine dust was used as a binder used to produce the matrix. W / B was set to $50 \%$, and then carbon was substituted to $0,5,10,15,20(\%)$ levels. As test items, unit weight, water absorption, flowability, flexural strength, compressive strength, thermal conductivity and fine dust concentration were measured. [Table 1] shows the experimental factors and levels.

Table1 Experimental factors and levels

\begin{tabular}{|c|c|c|}
\hline Experimental factor & Experimental level & \\
\hline Binder & $\begin{array}{l}\text { Blast furnace slag(BFS), Powdered activated } \\
\text { carbon(PAC) }\end{array}$ & 2 \\
\hline $\mathrm{W} / \mathrm{B}$ & $50($ wt. \%) & 1 \\
\hline Mixing ratio of $\mathrm{PAC}$ & $0,5,10,15,20 \quad$ (wt.\%) & 5 \\
\hline Curing condition & $\begin{array}{c}\text { Constant temperature-Humidity curing } \\
\left.\text { (Temp. } 20 \pm 2^{\circ} \mathrm{C}, \text { Hum. } 60 \pm 5 \%\right)\end{array}$ & 1 \\
\hline Test items & $\begin{array}{c}\text { Unit weight, Water absorption, Flowability, Thermal } \\
\text { conductivity, flexural strength, Compressive strength, } \\
\text { Fine dust concentration(PM 10, PM 2.5) }\end{array}$ & 8 \\
\hline
\end{tabular}

\subsection{Using materials}

\subsubsection{Blast furnace slag}

- The ground granulated blast furnace slag used in this study was used with three types of blast furnace slag powder with a density of $2.92 \mathrm{~g} / \mathrm{cm}^{3}$ and a fineness of $4,640 \mathrm{~cm} / \mathrm{g}$. The chemical composition of blast furnace slag is $\mathrm{CaO} 52.60 \%$ and $\mathrm{SiO}_{2} 28.70 \%$, showing a high proportion. The content of $\mathrm{MgO}$ and $\mathrm{SO}_{3}$ specified in $\mathrm{KS}$ F 2563 is 2.1 and $4.1(\%)$, respectively. [Table 2] shows the chemical composition of blast furnace slag in a table.

Table1 Chemical composition of blast furnace slag

\begin{tabular}{|c|c|c|c|c|c|c|c|}
\hline \multicolumn{1}{|c|}{ Chemical composition (\%) } \\
\hline $\mathrm{SiO}_{2}$ & $\mathrm{Al}_{2} \mathrm{O}_{3}$ & $\mathrm{Fe}_{2} \mathrm{O}_{3}$ & $\mathrm{CaO}$ & $\mathrm{MgO}$ & $\mathrm{SO}_{3}$ & $\mathrm{TiO}_{2}$ & $\mathrm{Cl}^{-}$ \\
\hline 28.7 & 9.5 & 0.6 & 52.6 & 2.1 & 4.1 & 0.7 & - \\
\hline
\end{tabular}




\subsubsection{Powdered activated carbon}

- Activated carbon is an aggregate of amorphous carbon with developed micropores made from carbonaceous materials such as palm kernels, woods, lignite, bituminous coal, etc., and has a high specific surface area by forming micropores of molecular size through the activation process. Activated carbon has a large surface area of $1,000 \mathrm{~m}^{2}$ or more per unit area, and the functional groups of carbon atoms on the surface have the property of adsorbing molecules of a substance to be adsorbed by the attraction of liquid or gas around them. The density of powdered activated carbon used in this study is $0.43 \mathrm{~g} / \mathrm{cm}^{3}$ and the specific surface area is $1,135 \mathrm{~m}^{2} / \mathrm{g}$. [Table 3] is the chemical composition of powdered activated carbon.

Table2 Chemical composition of Powdered activated carbon

\begin{tabular}{|c|c|c|c|c|c|c|c|}
\hline \multicolumn{8}{|c|}{ Chemical composition (\%) } \\
\hline $\mathrm{SiO}_{2}$ & $\mathrm{Al}_{2} \mathrm{O}_{3}$ & $\mathrm{Fe}_{2} \mathrm{O}_{3}$ & $\mathrm{CaO}$ & $\mathrm{MgO}$ & $\mathrm{SO}_{3}$ & $\mathrm{TiO}_{2}$ & $\mathrm{Cl}^{-}$ \\
\hline 11.5 & 2.9 & 17.8 & 19.2 & 2.2 & 7.8 & - & - \\
\hline
\end{tabular}

\subsection{Experimental method}

Among the test items, fluidity, water absorption, density, thermal conductivity, flexural strength and compressive strength were performed according to the test methods defined in the KS standard. In the case of the fine dust concentration measurement test, since there was no test method, the self-measurement method proposed by our university was used. The fine dust measurement method is a method of placing a fine dust adsorption type matrix, placing it in a sealed chamber together with a fine dust meter, and injecting fine dust into the chamber using a fine dust generator. The measurement time was measured every 10 minutes, and fine dust PM10 and PM2.5 were measured. [Figure 3] is the experimental equipment and method.
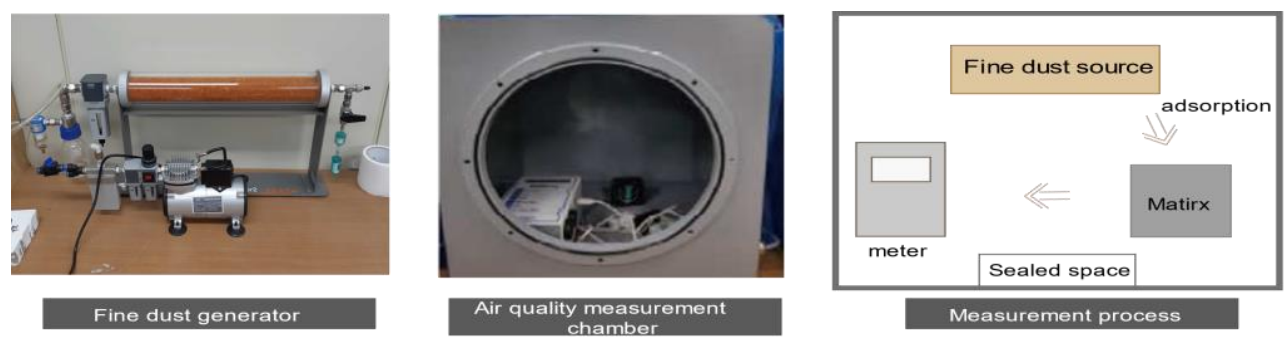

Figure 3 Fine dust adsorption equipment and test method

\section{Results}

\subsection{Density and adsorption}

[Figure 4] shows the unit weight and the water absorption of the cured product with the mixing ratio of powdered activated carbon. As the mixing ratio of powdered activated carbon increases, the density tends to decrease. It is considered that this is because material of powdered activated carbon has a high water absorption. When compared to plain, The unit weight of the cured body decreases, but the water absorption increases because of the high water absorption of the powdered activated carbon. but carbon may generate water through catalysis.

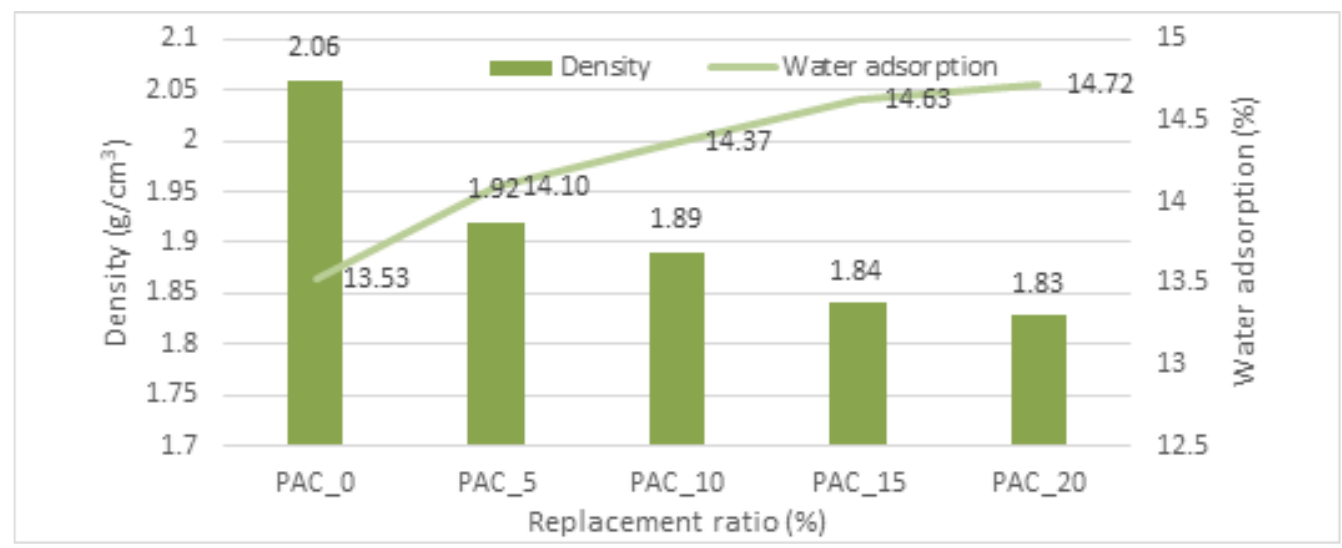

Figure 4 Density and water adsorption 


\subsection{Flowability}

[Figure 5] is a graph measuring the flowability follow the mixing ratio of powdered activated carbon. As a result of the measurement, it was found that the flowability tended to decrease as the mixing ratio of powdered coal increased. In the case of plain, when the flow test was in progress, the paste overflowed before the 25 compactions were completed, and measurement was not possible. In subsequent experiments, it was determined that the amount of powdered activated carbon was relatively large, and the fluidity decreased while absorbing the blended water.

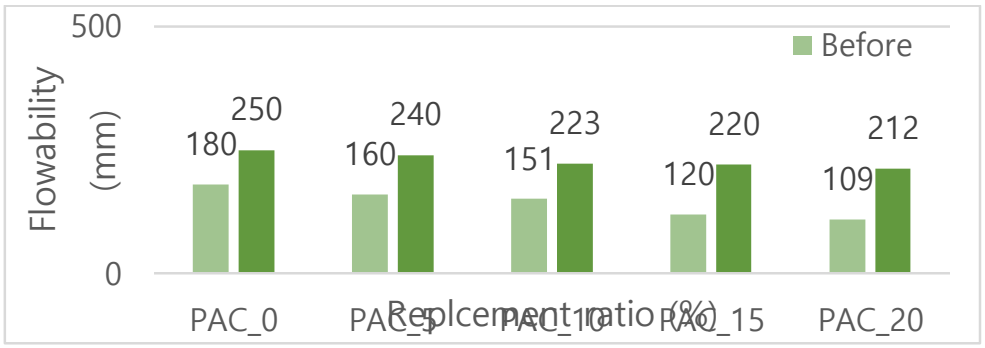

Figure 5 Flowability

\subsection{Thermal conductivity}

[Figure 6] is a graph measuring the thermal conductivity follow the powdered activated carbon content. As a result of the measurement, as the mixing ratio of powdered activated carbon increases, the thermal conductivity tends to decrease. It is believed that this is the result of pores occurring inside due to material properties. As curing proceeds, the value of thermal conductivity decreases. Pores are created as the moisture inside evaporates as it passes through the matrix.

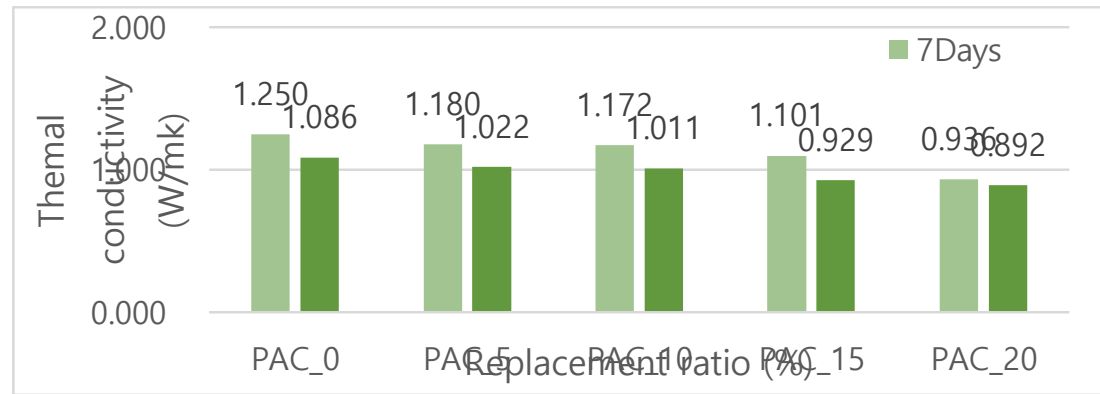

Figure 6 Thermal conductivity

\subsection{Flexural and compressive strength}

[Figure 7, Figure 8] show the flexural and compressive strength follow the mixing ratio of powdered activated carbon. As the mixing ratio of powdered activated carbon increases, the flexural and compressive strength tends to decrease. According to the results obtained in 3.1 and 3.2, the density is decreased and the strength is decreased at the pore is generated inside. According to existing literature, it is recommended to use about $3 \sim 10 \%$ when using powdered activated carbon. If the substitution is performed up to $20 \%$, the strength is greatly reduced, and it is considered that a proper mixing ratio should be used in consideration of economical efficiency.

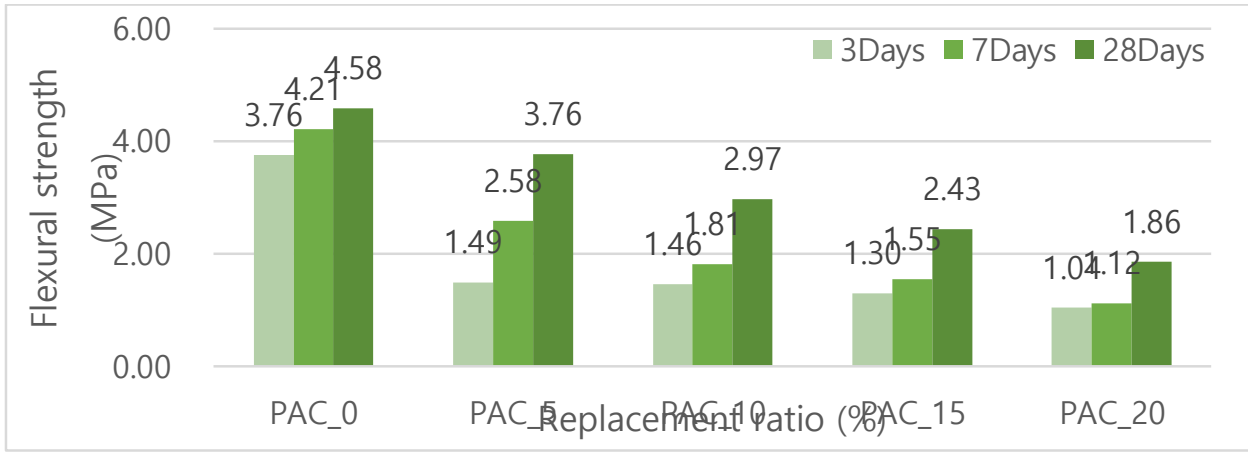

Figure 7 Flexural strength 


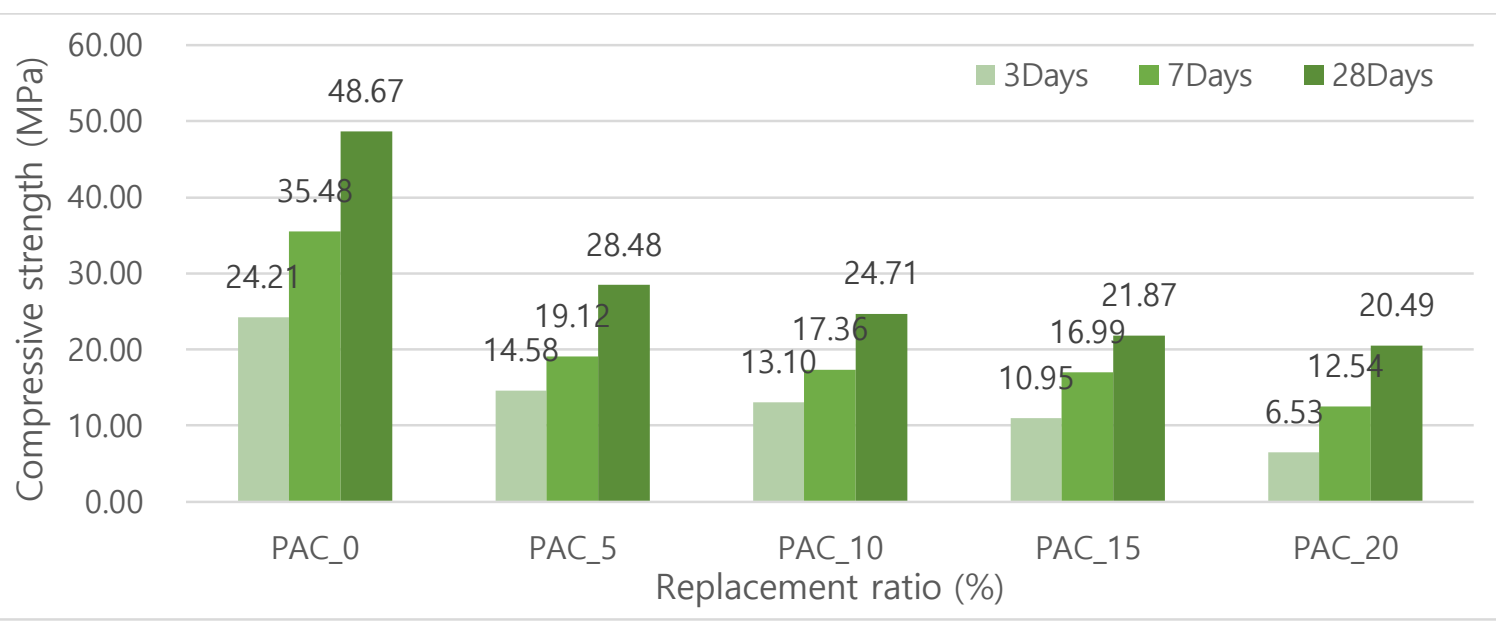

Figure 8 Compressive strength

\subsection{Fine dust concentration (PM10, PM2.5)}

[Figure 9, Figure 10] shows the fine dust concentration follow the mixing ratio of PAC. The fine dust concentration tends to decrease as the powdered activated carbon mixing ratio increases. It seems that the mixing rate of carbon increases and it affects the reduction of fine dust concentration. However, the reduction rate of the fine dust concentration is not large. It is considered that the anatase type is more effective than the powdered activated carbon in reducing the pollutants. Although it has been effective in reducing fine dust concentration, it seems that the effect is not excellent. Considering economical efficiency, it seems reasonable to use anatase type.

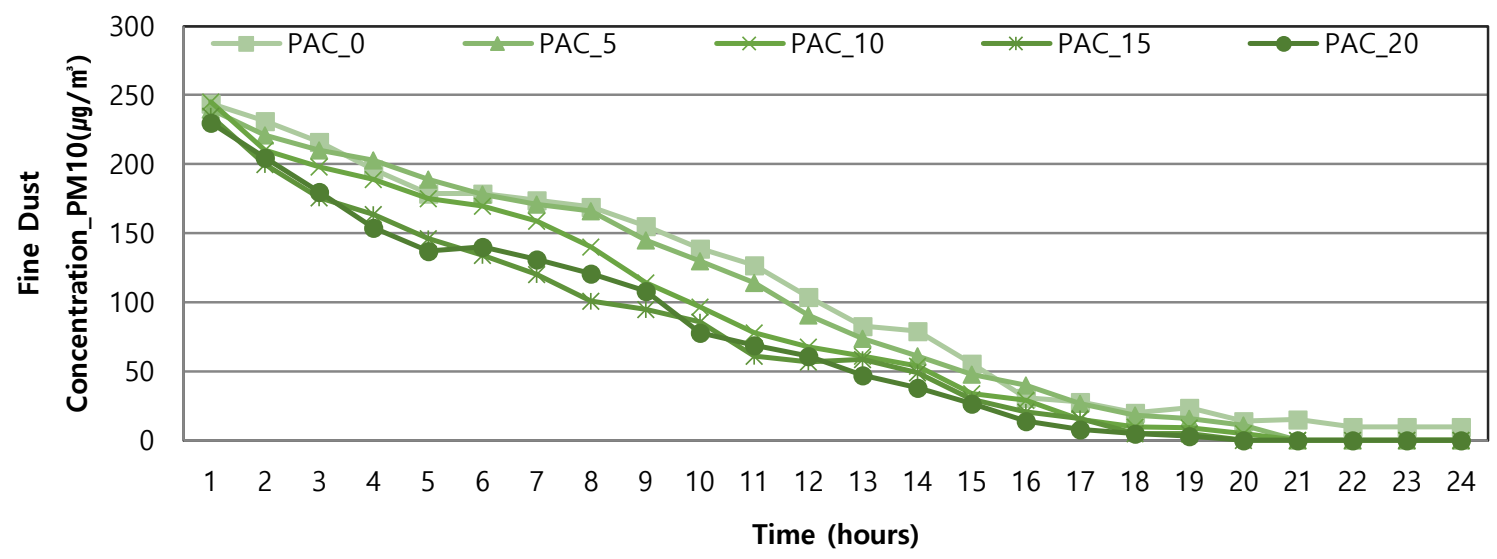

Figure 9 Fine dust concentration PM10

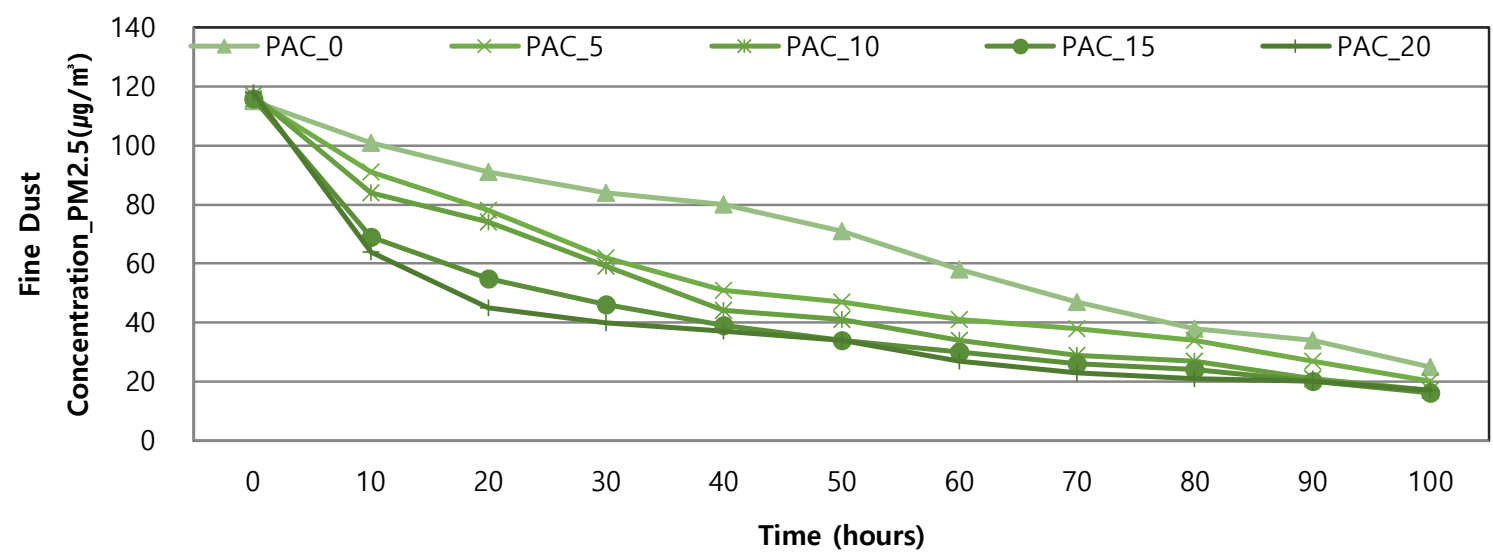

Figure 10 Fine dust concentration PM2.5 


\section{Conclusions}

This study is a basic experiment to fabricate fine dust absorption type products to solve social problems with fine dust affecting air pollution. Experiments were carried out for the analysis of matrix follow the mixing ratio of powdered activated carbon. The results are as follows. As the powdered activated carbon increases, the unit weight and the absorption ratio decrease and the absorption ratio increases. The Flowability decreases as the powdered activated carbon absorbs the compounding water. As the substitution ratio of powdered activated carbon increases, the strength tends to decrease.

The thermal conductivity decreases as the mixing rate increases due to the occurrence of pores as the matix progresses. As the curing progresses, the thermal conductivity decreases. When powdered activated carbon was used, the catalytic action occurred while decreasing the fine dust concentration, but the effect was not good. Considering the resultant value and the unit price of powdered activated carbon, the proper mixing ratio should be used between 5 and $10 \%$.

\section{Acknowledgements}

This article was performance by the research grant of 2018 Korea Scientific Research Foundation [Project No. 2018R1A2B6006764].

\section{References}

1. Kang HH, Legal Review on Fine Dust for Protection of People's Right to Health, Korean Environmental Law Society. 2016; 38(1):159-193.

2. Pak MS, Study on the association of fine dust between regions, Korean Society for Data Analysis. 2019; 21(3):1169-1181.

3. National Institute of Environmental Research: Living Environment Information Center, Importance of indoor air quality, 2019.

4. Wenming shi, Cong Liu, Dan Norback, Qihong Deng, Chen Huang, Hua Qian, et al. Effects of fine partivulate matter and its constituents on childhood pneumonia: a cross-sectional study in six Chinese cities. 2018 Oct;392(S79) 79. DOI: https://doi.org/10.1016/S0140-6736(18)32708-9

5. Small but huge bumps. (2018). Science Trends. Retrieved from http://www.etnews.com/ 20181116000162

6. Lee WA, Yang J, Yu JS, Lee JY. A study on the Property of Photocatalytic concrete, Korea Concrete Institute. 2002 May;14(1):575-580.

7. Kim YK, Hong SJ, Lee KB, Lee SW. Evaluation of NOx Removal Efficiency of Photocatalytic Concrete for Road Structure, International Journal of Highway Engineering, 2014 Oct;16(5). DOI: 10.7855/IJHE.2014.16.5.049

8. Pyeon SJ, Lee SS. Pore Characterisitics and Adsorption Performance Evaluation of Magnesium Oxide Matrix by Active Carbon Particle Size. Korea Institute of Construction, 2018 May;18(1):59-67.

9. Pyeon SJ, Lim HU, Lee SS. Evaluation of Decreasing Concentration of Radon Gas for Indoor Air Quality with Magnesium Oxide Board using Anthracite. Korea Institute of Construction, 2018;18(1):915.

10. Kyoung IS, Pyein SJ, Lee SS. Properties of matrix using TiO2 photocatalyst for improving air quality, International Journal of Innovative Technology and Exploring Engineering, 2019 Jun;852(8):784-788 